\title{
EXPRESSION OF MODIFIED RECOMBINANT HUMAN ERYTHROPOIETIN IN CHO-K1 CELLS AND ITS IN VITRO PROLIFERATION ASSAY IN TF-1 CELLS
}

\author{
Adi Santoso ${ }^{1 *}$, Endah Puji Septisetyani ${ }^{1}$, Edy Meiyanto ${ }^{2}$, \\ Dyaningtyas D.P. Putri ${ }^{2}$, Ratih Asma Ningrum ${ }^{1}$
}

\begin{abstract}
${ }^{1}$ Research Center for Biotechnology, Indonesian Institute of Sciences Jl. Raya Bogor KM 46 Bogor, 19611, Indonesia ${ }^{2}$ Faculty of Pharmacy, Gadjah Mada University Sekip Utara Yogyakarta, 55281, Indonesia
\end{abstract}

Submitted: $12-09-2013$

Revised: 25-11-2013

Accepted: 03-12-2013

${ }^{*}$ Corresponding author Adi Santoso

Email : adi_santoso1@yahoo.com

\begin{abstract}
Erythropoietin (EPO) is a $30 \mathrm{kDa}$ glycoprotein hormone which is important for red blood cells maturation. EPO consists of 165 amino acids and possesses $3 \mathrm{~N}$-linked carbohydrate chains. Recombinant human erythropoietin (rHuEPO), such as epoetin-a and epoetin- $\beta$, have been used for many years to treat anemia in patients with chronic renal failure, systolic heart failure, HIVAIDS, or cancer. In vivo stability of rHuEPOs were low due to rapid metabolisms by galactosyl receptor of the hepatocytes. Previously, a novel erythropoiesis stimulating protein (NESP) called darbapoetin-a (DARB) which possesses two additional Nlinked glycosylation had been studied. It was observed that NESP showed better in vivo stability and biological activity compared to the unmodified form (containing only $3 \mathrm{~N}$-linked carbohydrate chains). Based on the above study, we attempted to synthesize recombinant human EPO (rHuEPO) by generating $\mathrm{CHO}-\mathrm{K} 1$ cell lines expressing codon-optimized human epo open reading frame (ORF) in CHO-K1 cells. The ORF was modified to contain $5 \mathrm{~N}-$ linked carbohydrate chains. The media obtained from CHO-K1 cell culture was collected and diafiltrated with the use of tangential flow filtration. The rHuEPO protein containing polyhistidine tag was purified using affinity chromatography. An SDS/PAGE and Western blotting analyses confirmed that the purified protein was the modified rHuEPO. MTT based proliferation assay was conducted in TF- 1 bone marrow cell line as a model. The result showed that the modified rHuEPO was able to enhance TF-1 cells proliferation.
\end{abstract}

Key words: $\mathrm{CHO}-\mathrm{K} 1$, erythropoietin, glycosylation, MTT assay and TF-1 cell line.

\section{INTRODUCTION}

Erythropoietin (EPO) is one of protein hormones that commonly used in anemia caused by chronic renal failure (Lotscher, 2005; Pinevich and Petersen, 1991), systolic heart failure (Swedberg et al., 2013), HIV-AIDS, and cancer (Helena et al., 2006). It supports the production of red blood cells (Durocher and Butler, 2009; Goldwasser, 1975). Despite many efforts to synthesize this protein in many different expression systems, production of recombinant human EPO (rHuEPO) still relies on chinese hamster ovary $(\mathrm{CHO})$ derived cells (Kiss et al., 2010).

Endogenous human EPO EPO is a 30$38 \mathrm{kDa}$ glycoprotein (exact molecular weight depends on the degree of glycosylation) in amino acid single polypeptide chain containing two disulphide bonds. The remaining $40 \%$ of the EPO mass consists of carbohydrate covalently attached at three $\mathrm{N}$-linked sugar chain at Asn 24, 38 and 83, and one O-linked sugar chain at Ser126 (Skibeli et al., 2001; Egrie and Brown, 2001).

Glycosylation of EPO does not correspond to its in vitro activity, but it significantly contributes to the enhancement of in vivo stability and activity (Egrie and Browne, 2001). Functionally, glycosylation has been shown to influence a variety of critical biological processes at both the cellular and protein levels including its stability and long residence in body (Liu, 1992). Structurally, which $60 \%$ of the molecule composed of 165 
glycosylation is highly complex due to the fact that there can be heterogeneity with respect to the site of glycan attachment (macroheterogeneity) and with respect to the glycan's structure (microheterogeneity) (Sears and Wong, 1998). With regard to this circumstances, the efforts to synthesize rHuEPO with higher in vivo stability and biological activity by modification of its glycosilation pattern was studied (Egrie and Browne, 2001). A novel erythropoiesis stimulating protein (NESP) called darbepoetin$\alpha$ was synthesized by changing of 5 amino acids (Ala30Asn, His32Thr, Pro887Val, Trp88Asn and Pro90Thr) in the invariant amino acids core (Egrie and Browne, 2001) allowing for additional oligosaccharide attachments at asparagine residues at position 30 and 88 . The attachment of these oligosaccharides contributed to addition of molecular weight to approximately $37 \mathrm{kDa}$. With more carbohydrate content, NESP shows higher in vivo stability and activity compared to those epoetins (Egrie and Browne, 2001; McDougall, 2002).

In line with the previous study (Egrie and Browne, 2001), in this current study, we report the expression of hEPO in CHO-K1 cells. Under the control of the CMV promoter, codon optimized of human epo gene containing five N-linked oligosaccharide chains was subcloned into PJ603 expression plasmid system. Protein rHuEPO secreted into the culture medium was purified using immobilized metal affinity chromatography (IMAC) and analyzed using Western blot. In vitro analysis using bone marrow TF-1 cell line was also performed and discussed.

\section{MATERIALS AND METHODS Cell culture and reagents}

CHO-K1 cells were obtained from Prof. Masashi Kawaichi, Nara Institute of Science and Technology (NAIST), Japan. CHO-K1 cells were cultured in Nutrient Mixture F-12 Ham (F12) media (Sigma N6658) supplemented with $10 \%$ of fetal bovine serum (FBS, Sigma), 100U of benzylpenicillin and $100 \mu \mathrm{g}$ of streptomycin (Gibco, Invitrogen) in an incubator with addition of $5 \% \mathrm{CO}_{2}$ at $37^{\circ} \mathrm{C}$. Cells were passaged every 2-3days. TF-1 cells (EC93022307-FO) were obtained from Saibou, Japan. TF-1 cells were grown in RPMI (Roswell
Park Memorial Institute) 1640 media supplemented with $2 \mathrm{mM}$ of L-glutamine (Sigma), 10\% of FBS (Gibco, Invitrogen), 100U of benzylpenicillin-100 $\mathrm{gg}$ of streptomycin (Gibco, Invitrogen), and $5 \mathrm{ng} / \mathrm{mL}$ granulocyte macrophage-colony stimulating factor (GMCSF, Invitrogen) in an incubator with addition of $5 \% \mathrm{CO}_{2}$ at $37^{\circ} \mathrm{C}$. Cells were passaged every 2-3day. Epoetin- $\alpha$ (3000IU/mL, Hemapo) from PT. Kalbe Farma (Indonesia) was used as a positive control. Antibiotics G418 (Geneticin) was obtained from Sigma.

\section{Expression of rHuEPOin CHO-K1 cells}

Codon optimized of human epo gene containing five $\mathrm{N}$-linked carbohydrate chains was synthesized and subcloned into PJ603 expression plasmid system by DNA 2.0 (pJ-EPO). CHO-K1 cells were transfected with $\mathrm{pJ}$-EPO recombinant plasmidby using Lipofectamin 2000(Invitrogen) according to manufacturer's protocol. Stable expressing transformants were screened by using $1,000 \mathrm{ng}$ of G418. In addition, single clone cells were cultured in F12 medium supplemented with $10 \%$ of fetal bovine serum (FBS, Sigma), $100 \mathrm{U}$ of benzylpenicillin $100 \mu \mathrm{g}$ of streptomycin (Gibco, Invitrogen) and 1.000ng of G418.

\section{Ultrafiltration and purification}

About $100 \mathrm{~mL}$ of supernatant of culture medium was applied on diafiltration by using tangential flow filtration (Pall). Concentrated supernatant was then purified by using $\mathrm{Ni}$ Sepharose column (Histrap FF, GE Healthcare) and reconcentrated by using ultra centrifugal filter (Amicon, Merck) for Western blot. The recombinant protein rHuEPO resulted from the purification steps above was used for in vitro proliferation assay using TF-1 cell line.

\section{Relative quantitation of rHuEPO}

Epoetin- $\alpha$ (45IU) and bovine serum albumin with various concentrations $(25,50$, 100,150 and $200 \mathrm{ng}$ ) were subjected into a $12 \%$ of SDS-PAGE (sodium dodecyl sulfate polyacrylamide gel electrophoresis) gel analysis. The gel was stained using CBB (coomassie brilliant blue) solution (Bio-Rad). Area under curve-based analysis was determined by using ImageJ software. Relative concentration of 


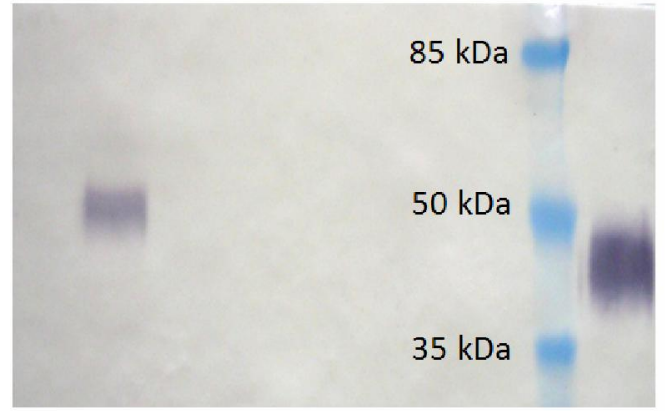

A

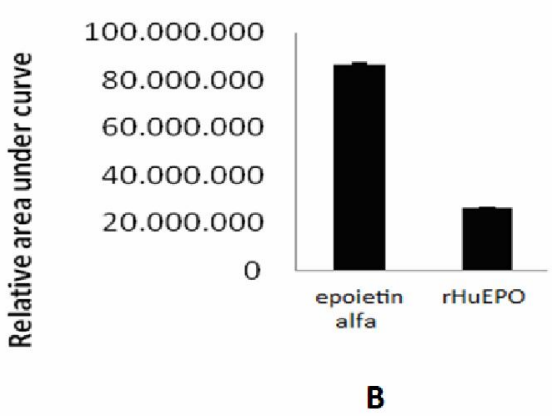

Figure 1. Detection of rHuEPO by Western blot. A) Supernatant of culture medium of CHO-K1 cells transfected with pJ-epo was purified by Ni-NTA agarose beads and concentrated by ultra centrifugal filter. rHuEPO, protein marker (M), and epoetin- $\alpha(\mathrm{H})$ were subjected to SDS PAGE and detected by Western blot. B) Relative area under curve of epoetin- $\alpha$ and rHuEPO bands were analyzed using ImageJ software.

epoetin- $\alpha$ was calculated by using BSA as standard. Relative concentration of epoetin- $\alpha$ was used to determine our modified rHuEPO concentration. As much as $15 \mu \mathrm{L}$ of $\mathrm{rHuEPO}$ and epoetin- $\alpha$ (45IU) were analyzed in $12 \%$ of SDS-PAGE gel. The proteins then were the transfered into nitro cellulose membrane (GE Healthcare) by wet transfer method. The membrane was soaked in blocking solution containing $5 \%$ of skim milk. After washing with tris buffer saline containing $0.1 \%$ tween (TBS-T), the membrane was soaked in primary human polyclonal anti-EPO antibodies (1:1000, Calbiochem). Following the next washing step, the membrane was soaked in anti rabbit alkaline phosphatase linkeded antibody as the secondary antibody (3:10,000, Promega) and then visualized by nitroblue tetrazolium chloride-5-bromo-4-chloro-1H-indol-3-yl dihydrogen phosphate (NBT-BCIP, Promega). The same analysis using Image $J$ was performed to obtain relative concentration of modified rHuEPO.

\section{MTT proliferation assay}

MTT (methylthiazol tetrazolium) proliferation assay of $\mathrm{rHuEPO}$ in TF-1 was done based on Hammerling et al. (1996).TF-1 cells were cultured in RPMI 1640 media (Sigma) supplemented with 2mM L-glutamin (Sigma), $10 \%$ of FBS (Gibco), 4mM 100U

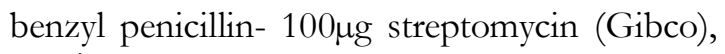
$5 \mathrm{ng} / \mathrm{mL}$ GM-CSF (Invitrogen) in $\mathrm{CO}_{2}$ incubator with $5 \% \quad \mathrm{CO}_{2}$ at $37^{\circ} \mathrm{C}$. One day before harvesting, the cells were washed with PBS and changed with medium without GMCSF. As much as $90 \mu \mathrm{L}$ of cells suspension were seeded in RPMI-1640 with serum and antibiotics respectively (without GM-CSF) into 96-well microtiter plates at a density of $2 \times 10^{5} \mathrm{cells} / \mathrm{mL}$. Cells were treated with $90 \mu \mathrm{L}$ of serial dilutions of modified rHuEPOand commercial epoetin- $\alpha$. After $48 \mathrm{~h}$ incubation, $20 \mu \mathrm{L}$ of $6 \mathrm{mg} / \mathrm{mL}$ of MT'T solution was added to the cells and incubated for $4 \mathrm{~h}$. Formazan as a product of MTT convertion was dissolved by $10 \%$ SDS in $0,01 \mathrm{M} \mathrm{HCl}$. The next day, optical density (OD) of each well was analyzed by microplate reader at $595 \mathrm{~nm}$. OD response was analyzed by substracting OD of treated well with OD of blank.

\section{RESULT AND DISCUSSION \\ Detection of rHuEPO}

The PJ603 recombinant plasmid containing codon optimized of human epo gene with five N-linked oligosaccharide chains was transfected into CHO-K1 cells using Lipofectamine 2000, and G418 resistance colonies were selected. Individual clones were isolated and screened for the expression of $\mathrm{hEPO}$ protein. One clone expressing hEPO 


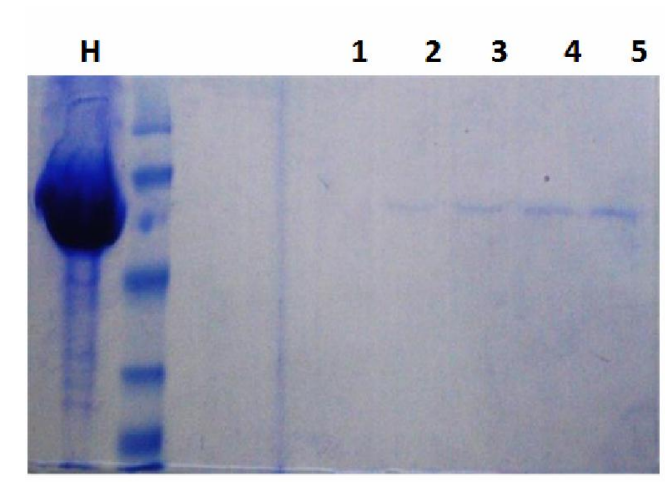

A

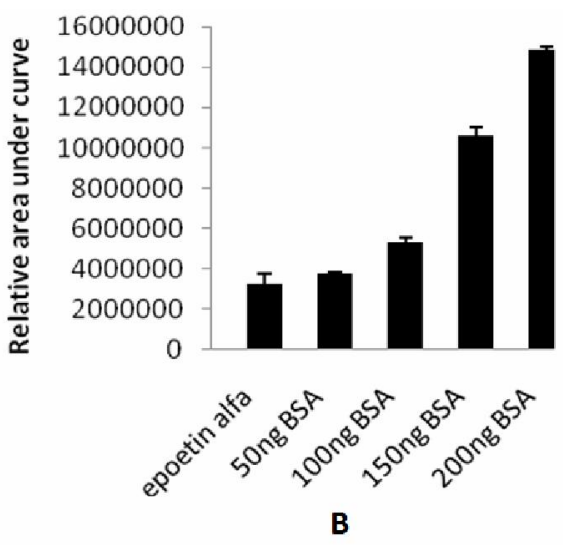

Figure 2. Detection of $\mathrm{rHuEPO}$ by CBB staining. A. $\mathrm{H}=$ epoetin- $\alpha$ (45 IU), $\mathrm{M}=$ protein marker, 1-5 = bovine serum albumin (BSA) 25, 50, 100, 150 and $200 \mathrm{ng}$ respectively; B. Relative area under curve of epoetin- $\alpha$ and BSA bands were analyzed by ImageJ software.

was used for subsequent functional study. The coding sequence of the therapeutically important human glycoprotein EPO was fused with a polyhistidine tag to enable easy, rapid purification. The expression of the human epo gene was placed under the control of CMV promoter. Following incubation in the presence of $5 \% \mathrm{CO}_{2}$ at $37^{\circ} \mathrm{C}$ for $2-3$ days, the expressed rHuEPO protein was secreted into the medium. The media were collected by centrifugation at $6000 \mathrm{rpm}$ for $5 \mathrm{~min}$ and the supernatant containing $\mathrm{rHuEPO}$ was collected while the cells were removed.

Following purification, the sample was run on SDS/PAGE and detected with Western blot analysis using polyclonal anti human EPO antibody. Eventhough, the molecular mass of the expressed $\mathrm{rHuEPO}$ is about $37 \mathrm{kDa}$, in this study, the signal of the expressed protein was detected above $50 \mathrm{kDa}$ protein marker due to denaturation and glycosylation (Figure 1), while epoetin- $\alpha$ which was used as positive control detected below $50 \mathrm{kDa}$ protein marker.

The remaining $40 \%$ of the native EPO mass consists of carbohydrate covalently attached at three $\mathrm{N}$-glycans sugar chains at Asn 24, 38 and 83, and one O-linkeded sugar chain at Ser126 (Browne et al., 1986; Davis et al., 1987; Miyake et al., 1977). Since the consensus sequences for $\mathrm{N}$-linked glycans was known (Asn-X-Ser/Thr where $\mathrm{X}$ is any amino acid except proline), we speculate that the increase in size of this molecular mass is attributed to the attachment of two additional oligosaccharides at asparagine residues positions 30 and 88 . The increase of this molecular mass increase the average carbohydrate content of the molecule from $38 \%$ to $50 \%$ (data not shown) and the maximum number of sialic acids from 14 to 22 (Egrie and Browne, 2001).

\section{Dertermination of rHuEPO concentration}

Since we were not able to detect the presence of $\mathrm{rHuEPO}$ protein in CBB staining, we modified this detection using combination of Western blot and CBB staining. As much as $45 \mathrm{IU}$ of epoetin alpha was quantified using BSA at concentration of 50,100, 150 and 200ng as protein control in SDS/PAGE gel (Figure 2). Using ImageJ software, it was found that epoetin- $\alpha$ in Hemapo was about $2.9 \mathrm{ng} / \mu \mathrm{L}$. By knowing weight quantity of epoetin- $\alpha$, we then quantify the concentration of our rHuEPO sample by running the $10 \mathrm{x}$ concentrated sample in SDS/PAGE using epoetin- $\alpha$ as protein control. Calculated using the software, it is predicted that the concentration of rHuEPO was approximately $0.09 \mathrm{ng} / \mu \mathrm{L}$.

\section{Analysis of rHuEPO in vitro proliferation activity}

Following characterization of hyperglycosylated $\mathrm{rHuEPO}$, in vitro biological activity was performed. For this purpose the human erythroleukemia cell line TF-1 was employed for determination of proliferative stimulation 
Table I. In vitro activity of epoetin- $\alpha$ on proliferation of TF-1 cells.

\begin{tabular}{ccc}
\hline IU/well & ng/well* & OD \pm SD** \\
\hline 0.1 & 0.1 & $0.037 \pm 0.002$ \\
0.2 & 0.2 & $0.046 \pm 0.006$ \\
0.4 & 0.3 & $0.051 \pm 0.002$ \\
0.8 & 0.8 & $0.059 \pm 0.012$ \\
\hline
\end{tabular}

* Calculated based on epoietin- $\alpha$ activity (about $1 \mathrm{IU} / \mathrm{ng}$ ).

** OD was analyzed by substracting the blank well OD from the treated ones.

Table II. In vitro activity of modified rHuEPO on proliferation of TF-1 cells.

\begin{tabular}{ccc}
\hline $\boldsymbol{\mu L} /$ well & ng/well* & OD \pm SD** \\
\hline 0.33 & 0.03 & $0.035 \pm 0.002$ \\
0.67 & 0.06 & $0.048 \pm 0.005$ \\
1.33 & 0.12 & $0.036 \pm 0.002$ \\
2 & 0.18 & $0.046 \pm 0.002$ \\
2.67 & 0.24 & $0.067 \pm 0.002$ \\
\hline
\end{tabular}

* Calculated based on rhEPO concentration (about $0.09 \mathrm{ng} / \mu \mathrm{L}$ ).

** OD was analyzed by substracting the blank well OD from the treated ones.

induced by rHuEPO protein. MTT proliferation assay of epoetin- $\alpha$ on TF-1 cells indicated that epoetin- $\alpha$ at concentration below 1 IU enhanced proliferation of TF-1 cells (Table I). However, when concentration of epoetin- $\alpha$ at more than $1 \mathrm{IU}$ the proliferation of TF-1 cells decreased (data not shown).

Purified rHuEPO sample that had been synthesized in CHO-K1 cells showed enhancement of TF-1 proliferation. Moreover, activity of our rHuEPO was comparable to epoetin- $\alpha$ (Table II). Considering the concentration of rHuEPO was about $0.09 \mathrm{ng} / \mu \mathrm{L}$, thus, the activity of $0.18 \mathrm{ng}$ of expressed rHuEPO was similar to $2 \mathrm{ng}$ of epoetin- $\alpha$ (Table I and II). As additional information, both epoetin- $\alpha$ in Hemapo and our modified rHuEPO sample contain small amount of albumin as stabilizer.

The development of hEPO for the correction of anemia related diseases is a dramatic example of how much hEPO research has been progressing. Initially, it took 20 years to purify a few milligrams of erythropoietin from over 2.5L of urine from patients with aplastic anemia (Miyake et al., 1977). The first replacement therapy for anemia patient with chronic renal failure was to administer native erythropoietin from human urinary. The activity of human urinary EPO is 70,000 $\mathrm{IU} / \mathrm{mg}$ (Jelkmann, 2006). This massive effort provided the basis for the cloning of the human erythropoietin gene in 1985 and the possibility for large-scale production (Jacobs, et al., 1985). Since then, the use of recombinant hEPO is widely used for treatment of anemia in patients suffer from anemia related diseases (Lotscher, 2005; Pinevich and Petersen, 1991; Swedberg et al., 2013). This epoetin- $\alpha$ shows higher in vivo activity than that of urinary EPO, about $200.000 \mathrm{IU} / \mathrm{mg}$, probably due to more complete glycosylation (Jelkmann, 2006). In line with this, currently, one of the most significant progresses in EPO research is the development of darbapoietin, an EPO molecule with additional glycosylations resulting in a significantly longer half-life and a reduced dosing frequency.

Related to the previous study (Egrie and Browne, 2001), in this study, we expressed modified rHuEPO with 2 addition of N-linked glycosylations in adherent CHO-K1 cells base. The expressed protein was detected by Western blotting above $50 \mathrm{kDa}$ which was higher than that of epoetin- $\alpha$. Molecular weight of our modified rHuEPO supposed to be similar to NESP, about $37 \mathrm{kDa}$. Various studies have reported that expression of heterologous 
glycosylated recombinant protein may result in a greater molecular mass than it should be. This may be caused by the degree in the glycosylation itself or denaturation. This result was similar to that had been reported by Gross and Lodish (2006). The difference of molecular weight of our modified $\mathrm{rHuEPO}$ and epoetin- $\alpha$ was about $7.5 \mathrm{kDa}$. This additional molecular weight might be contributed from two additional N-linked carbohydrate chains (about $6.6 \mathrm{kDa}$ ) and 6xhistag sequence (about $1 \mathrm{kDa}$ ) (Egrie and Bowne, 2001; Terpe, 2003).

To verify that glycosylation was indeed contributed to an increase of molecular weight, we use enzymatic removal of the glycans moiety of the expressed protein with PNGase F. PNGase F has been utilized extensively for demonstrating shifts in SDS/PAGE mobilities as an indication of $\mathrm{N}$-glycosylation. Digestion with PNGase $\mathrm{F}$ resulted in a band with a molecular mass approximately corresponds to the molecular mass of the polypeptide backbone and both our modified rHuEPO and epoetin- $\alpha$ appeared in the same size which is about $20 \mathrm{kDa}$. Thus, it is very likely that our modified rHuEPO was the hyperglycosylated EPO with 2 addition of carbohydrate chains (Santoso et al., 2012).

Proliferation assay of our modified rHuEPO and epoetin- $\alpha$ were done in human erythroleukemia TF-1 cells. It has been reported that in vitro proliferation assay of EPO in TF-1 cells show high accuracy (Hammerling et al., 1996). Treatment of TF-1 cells with EPO in $24 \mathrm{~h}$ down-regulates the EpoR and reach a peak in 6h. Moreover, in TF-1 cells, EPO only stimulates proliferation for short period of time (Kitamura et al., 1989). In this study, the result indicated that our modified rHuEPO showed comparable proliferative activity with that oh epoetin- $\alpha$. Epoetin- $\alpha$ showed enhancement of TF-1 cells proliferation at concentration below $1 \mathrm{IU}$ and its activity declines at concentration more than 1IU. However, concentration of epoetin- $\alpha$ used in this study was remained higher than its physiologic concentration range (Urabe et al., 1987).

It has been shown that the addition of carbohydrate is required for secretion, stability, delay clearance and biosynthesis (Sola et al., 2010). However, the carbohydrate is not essential for the biological activity of EPO in vitro, indicating that only the polypeptide is involved in binding to the EPO receptor. On the other hand, proper glycosilation of EPO is absolutely critical in in vivo condition (Egrie and Browne, 2001). Since in our current experiment the functional analysis performed was in vitro study, thus the addition of 2-oligosaccharide attachments (at position 30 and 88 ) has no effect.

Previous study reported that that two additional N-linked glycosylations of NESP causes its molecule to be more bulky. Thus, it makes NESP to have lower in vitro activity than that of epoetin- $\alpha$ (Egrie and Browne, 2001). However, excessive amount of NESP shows similar in vitro activity with that of epoetin- $\alpha$ (Elliot et al., 2004). Affinity of NESP to its receptor (EpoR) is lower than that of epoetin$\alpha$, but activity of NESP in vivo is higher than epoetin- $\alpha$. With lower binding affinity to EpoR, NESP is also released slower (Gross and Lodish, 2006). Moreover, with more glycosyl groups of NESP, the enzymatic digestion rate of NESP by galactosyl receptor in liver is lower than epoetin- $\alpha$. Altogether, the resultant in vivo activity of NESP is greater than that of epoetin$\alpha$; and modification of $r H u E P O$ is very important for improving its stability (Jelkmann, 2006).

\section{CONCLUSION}

In this study we expressed modified rHuEPO in CHO-K1 cells. The result showed that the modified rHuEPO enhanced TF-1 cells proliferation. In vitro proliferation assay indicated comparable values between our rHuEPO and epoetin- $\alpha$.

\section{ACKNOWLEDGEMENT}

This study was supported by the National Innovation Program (SiNas), Ministry of Research and Technology (Menristek) (grant No. RD 2013-096). The authors are grateful to Prof. Masashi Kawaichi for providing CHO-K1 cells.

\section{REFERENCES}

Browne JK., Cohen AM., Egrie JC., 1986, Erythropoietin: Gene Cloning, Protein Structure, and Biological Properties. Cold Spring Harb Symp Quant Biol 51:693-702. 
Davis JM., Arakawa T., Strickland TW., Yphantis DA., 1987, Characterization of Recombinant Human Erythropoietin Produced in Chinese Hamster Ovary Cells. Biochemistry 26: 2633-2638.

Durocher Y., Butler M., 2009, Expression Systems for Therapeutic Glycoprotein Production. Current Opinion in Biotechnology, 20, 700-707.

Egrie JC., Browne JK., 2001, Development and Characterization of Novel Erythropoiesis Stimulating Protein (NESP). Nephrol Dial Transplant., 16(Suppl 3), 3-13.

Elliot S., Egrie J., Browne J., Lorenzini T., Busse T., Rogers N., Ponting I., 2004, Control of rHuEPO Biological Activity: The Role of Carbohydrate, Exp. Hematol. 32:1146-1155.

Goldwasser, E., 1975, Erythropoietin and The Differentiation of Red Blood Cells. Fed Proc., 34(13) 2285-2292.

Hammerling U., Kroon R., Wilhelmsen T., Sjodin L., 1996, In Vitro Bioassay for Human Erythropoietin based on Proliferative Stimulation of an erythroid cell line and analysis of carbohydratedependent microheterogeneity, J. Pharm. Bio. Anal.14:1455-1469.

Helena DA., Jyothsna NL., Rao PJ., Rao GV., and Rao, KRSS., 2006, Therapeutic Implications of Recombinant Human Erythropoietin in Anaemic Related Clinical Manifestations. African J Biotechnology, 5(25), 2503-2509.

Jacobs K., Shoemaker C., Rudersdorf R., 1985, Isolation and characterization of genomic and cDNA clones of human erythropoietin, Nature, 313(6005):806-10.

Jelkmann W., 2006, Recombinant Erythropoietins The Role of Glycosylation in Receptor Binding, Business Briefing: European Kidney and Urological Disease p.15.

Jelkmann W., 2006, Recombinant Erythropoietin: The Role of Glycosylation in Receptor Binding, Business Briefing: European Kidney \& Urological Disease, 1-5.

Kiss Z., Elliot S., Jedynasty K., Tesar V., Szegedi J., 2010, Discovery and Basic Pharmacology of ErythropoiesisStimulating Agents (ESAs), Including the
Hyperglycosylated ESA, Darbepoetin Alfa: an Update of Rationale and Clinical Impact, Eur J Clin Pharmacol 66:331-340.

Kitamura T., Tojo A., Kuwaki T., Chiba S., Miyazono K., et al., 1989, Identification and Analysis of Human Erythropoietin Receptors on a Factor-Dependent Cell Line, TF-1, Blood 73: 375-380.

Liu, DT., 1992, Glycoprotein pharmaceuticals: scientific and regulatory considerations, and the US Orphan Drug Act. Trends Biotechnol, 10(4):114-120.

Lotscher NG., 2005, Anaemia Management in Dialysis Patients in Switzerland "AIMS". Basel: Dissertation Universitat Basel, 25-30.

Macdougall IC., 2002, Darbepoetin Alfa: A New Therapeutic Agent for Renal Anemia. Kidney International, 61, S55-61.

Miyake T., Kung CK., Goldwasser E., 1977, Purification of Human Erythropoietin. I Biol Chem 252:5558-5564.

Narhi LO., Arakawa T., Araki KH., Elmore R., Rohde MF. et al 1991, The Effect of Carbohydrate on The Structure and Stability of Erythropoietin. J. Biol. Chem, 266(34), 23022-23026.

Pinevich AJ., Petersen J., 1992, Erythropoietin Therapy in Patients With Chronic Renal Failure. West J Med, 157(2), 154-157.

Santoso A., Kitagawa NI., Wardiana A., Kusumawati A., Septisetyani EP., et al, 2012, Production of Pharmaceutic Protein Recombinant Human Erythropoietin with Modification of Glycosylation (in Indonesia), Proceeding of Insinas Ristek, Ministri of Research and Technology, Jakarta p. 181-186.

Sears P., Wong CH., 1998, Enzyme action in glycoprotein synthesis. Cell Mol Life Sci, 54(3):223-252.

Skibeli V., Nissen-Lie G., Torjesen P., 2001, Sugar profiling proves that human serum erythropoietin differs from recombinant human erythropoietin, Blood 98: 36263634.

Sola RJ., Griebenow K., 2009, Effects of Glycosylation on The Stability of Protein Pharmaceuticals. J.Pharm.Sci, 98(4), 12231245.

Sola, RJ., Griebenow, K., 2010, Glycosylation of Therapeutic Proteins: An Effective 
Strategy to Optimize Efficacy. BioDrugs, 24(1), 9-21.

Swedberg K., Young JB., Anand IS., Cheng S., Desai AS., et al., 2013, Treatment of Anemia with Darbepoetin Alfa in Systolic Heart Failure, N.Engl.J.Med 368:1210-1219.

Terpe K., 2003, Overview of Tag Protein Fusions: from Molecular and
Biochemical Fundamentals to Commercial Systems, Appl Microbiol Biotechnol 60:523-533.

Urabe A., Saito T., Fukamachi H., Kubota M., Takaku F., 1987, Serum Erythropoietin Titers in Anemia of Chronic Renal Failure and Other Hematological States, Int J Cell Cloning 5:202. 